\title{
Morphological Study of HDPE Prepared with the Highly Active Silica Supported $\mathrm{TiCl}_{4} / \mathrm{MgCl}_{2}$ Catalyst
}

\author{
Il KIM and Seong Ihl WoO* \\ Department of Chemical Engineering, Korea Advanced Institute \\ of Science and Technology, P. O. Box 131, \\ Cheongryang, Seoul, Korea
}

(Received February 6, 1989)

\begin{abstract}
Kinetic investigations were carried out on the effects of polymerization conditions and nature of aluminium alkyl cocatalyst on the morphology (size, shape, density, and texture) of nascent polyethylene synthesized with $\mathrm{TiCl}_{4} / \mathrm{MgCl}_{2} / \mathrm{SiO}_{2}$ catalyst. Depending on the nature of the cocatalyst, considerably different kinetic profiles are obtained. Fibrillar, globular, cobweb, ribbon-like, worm-like, and lamellar structures are identified according to the catalyst system and polymerization conditions. The formation of a worm-like texture is a common feature of the catalyst combined with $\mathrm{Al}\left(\mathrm{C}_{2} \mathrm{H}_{5}\right)_{3}$ at high catalyst efficiency, while globular texture is obtained at low catalyst efficiency. Polymerization at optimum temperature $\left(80^{\circ} \mathrm{C}\right)$ and $\mathrm{Al}\left(\mathrm{C}_{2} \mathrm{H}_{5}\right)_{3}$ concentration $(\mathrm{Al} / \mathrm{Ti}=60)$ without the addition of hydrogen produces a well-defined crystalline structure, folded lamella globule. A cobweb structure is observed when $\mathrm{AlEt}_{2} \mathrm{Cl}$ is used as the cocatalyst. The effect of polymerization conditions on the particle size distribution of nascent polyethylene is also investigated. Replication phenomenon was observed to depend on the catalyst yield and polymerization time. Generally, the average particle size of polymer particles becomes large as the rate of polymerization increases.

KEY WORDS Silica-Supported $\mathrm{TiCl}_{4} / \mathrm{MgCl}_{2}$ Catalyst / High Density Polyethylene / Polymer Texture / Polymer Particle Morphology Replication Phenomenon /
\end{abstract}

The morphology of a polymer particle synthesized in the presence of heterogenerous Ziegler-Natta catalysts is determined by a number of factors. ${ }^{1}$ Considerable understanding of the mechanistic paths by which polymer chains are assembled has been achieved through the work of many investigators. ${ }^{2-6}$ It is well known that progeny polymer particles appear to be obvious replicates of parent catalyst particles. ${ }^{7}$ Accordingly a number of workers have centered their research on the development of highly active catalysts showing excellent morphological characteristics.

Good and uniform morphological control of polymer particles is very important not only for readily fluidizing polymer particles in the fluidized reactor, but also for the feasible elimination of the pelletizing step in the polyolefine industry. From another point of view, controlling the polymer particle size is important since polymers finely grained or corsely grained may be desired depending on the application.

It has been reported that control of polymer particle size in the polymerization of ethylene can be achieved by using a catalyst support in a particular particle size range. ${ }^{8}$ Union Carbide recently developed highly active silica supported magnesium- titanium complex catalysts for the fluidized homo- and co-polymerization of ethylene and $\alpha$-olefins. ${ }^{9}$ Their patents describe that ethylene homo- and co-

\footnotetext{
* To whom all correspondence should be addressed.
} 
polymers prepared in the fluidized gas-phase polymerization process show excellent morphology. The polymer particles have ideal particle size distribution for fluidization with a relatively low level of fineness (diameter of particles $<125$ microns).

In the present study, several morphological parameters in the high-pressure slurry-phase ethylene polymerization with $\mathrm{TiCl}_{4} / \mathrm{MgCl}_{2} /$ $\mathrm{SiO}_{2}$ catalysts prepared according to the procedure of preparing an UNIPOL PE catalyst are discussed. Most researchers who have studied morphology so far have paid attention to the replication phenomena and polymer particle growth mechanism. Very little is shown in the literature on how kinetic behavior during polymerization can influence polymer particle size distribution and bulk density, and how the polymerization conditions influence the progeny polymer texture. Characterization of those parameters in a slurry-phase polymerization at the industrial operating conditions is the object of the present study.

\section{EXPERIMENTAL}

\section{Materials}

The source of materials, methods of purification, procedures for the preparation of catalyst are described elsewhere. ${ }^{10}$

\section{Polymerization}

Slurry polymerization was carried out in a 1 liter autoclave under a constant pressure of ethylene. A prescribed amount of cocatalyst and 0.5 liter of $n$-hexane were introduced into reactor in a nitrogen steram. After evacuation, ethylene was introduced at the polymerization temperature. Polymerization was started by breaking the glass ampoule containing the prescribed amount of catalyst. The rate of polymerization was determined from the rate of ethylene consumption, measured by a hotwire flowmeter with a recorder and a personal computer directly connected to a flowmeter through a AD converter. Detailed polymerization procedures have been previously described elsewhere. ${ }^{10}$

\section{Characterization}

The surface areas of dehydrated silica gel and supported catalyst were determined by the conventional BET method. The morphology of polyethylene was examined in a scanning electron microscope JEOL JSM-T20, using a sputtering techniques, and an optical microscope. To avoid the possibility that only a certain part of the polymer texture would be accentuated, SEM photographs of the same HDPE samples were taken at three other research centers. The bulk density and particle size distribution of polyethylene particles were measured according to ASTM D-1895 method B, and ASTM D-1921 method A, respectively.

\section{RESULTS AND DISCUSSION}

\section{Kinetics of Ethylene Polymerization}

Detailed kinetics of ethylene polymerization with silica supported magnesium-titanium complex catalyst were studied previously at our laboratory. ${ }^{10}$ Figure 1 shows the general kinetic behavior of the polymerization with the catalyst combined with $\mathrm{Al}\left(\mathrm{C}_{2} \mathrm{H}_{5}\right)_{3}, \mathrm{Al}(\mathrm{i}$ $\left.\mathrm{C}_{4} \mathrm{H}_{9}\right)_{3}$, and $\mathrm{Al}\left(\mathrm{C}_{2} \mathrm{H}_{5}\right)_{2} \mathrm{Cl}$. Depending on the nature of the cocatalyst, considerably different kinetic profiles and polymerization yields were obtained.

The catalyst combined with $\mathrm{Al}\left(\mathrm{C}_{2} \mathrm{H}_{5}\right) \mathrm{Cl}$ showed non-decay type rate profile. The rate of polymerization gradually increased to a constant value. This type of rate profile was shown by several first generation catalyst systems when used with $\mathrm{Al}\left(\mathrm{C}_{2} \mathrm{H}_{5}\right)_{2} \mathrm{Cl}$ as a cocatalyst for the polymerization of propylene. When $\mathrm{Al}\left(\mathrm{C}_{2} \mathrm{H}_{5}\right)_{3}$ or $\mathrm{Al}\left(\mathrm{i}-\mathrm{C}_{4} \mathrm{H}_{9}\right)_{3}$ was used as a cocatalyst for the $\mathrm{TiCl}_{4} / \mathrm{MgCl}_{2} / \mathrm{SiO}_{2}$ catalyst, a decaying-type polymerization rate curve was identified, where the deactivation fit well firstorder kinetics. 


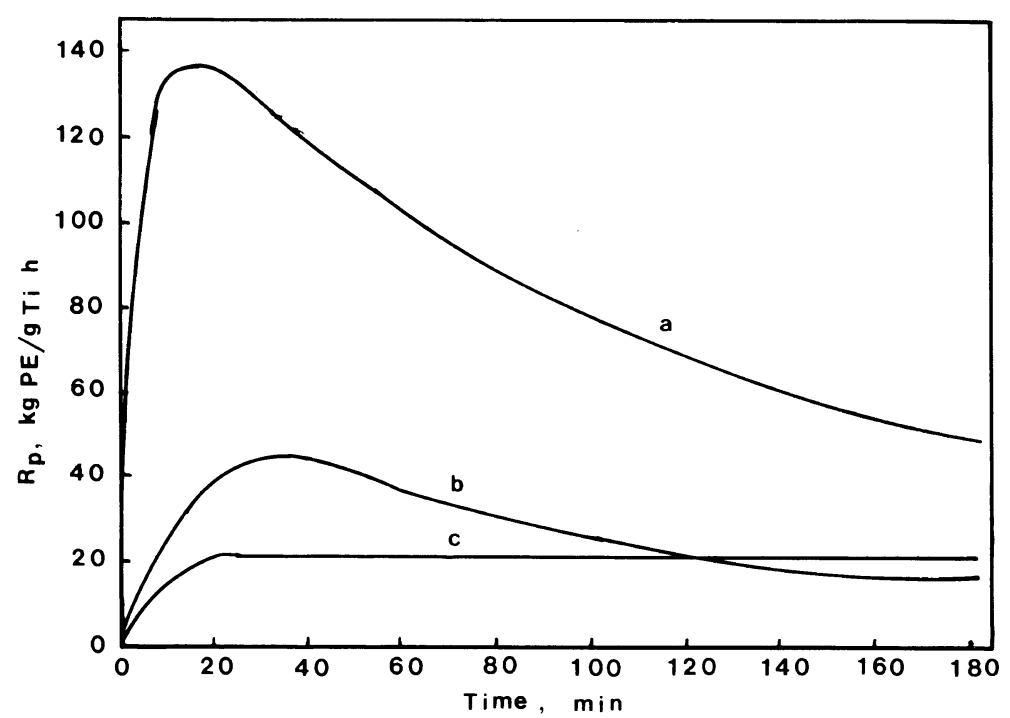

Figure 1. Polymerization rate profile depending on the nature of cocatalyst. Polymerization conditions: $T=80^{\circ} \mathrm{C} ; P=6.0 \mathrm{~kg} \mathrm{~cm}^{-2} ; P_{\mathrm{H} 2}=0.7 \mathrm{~kg} \mathrm{~cm}^{-2} ;[\mathrm{Ti}]=1.785 \times 10^{-5} \mathrm{moll}^{-1}$; (a) $\left[\mathrm{AlEt}_{3}\right]=4.35 \mathrm{mmoll}^{-1}$; (b) $\left[\mathrm{Al}(\text { iso- } \mathrm{Bu})_{3}\right]=2.35 \mathrm{mmoll}^{-1}$; (c) $\left[\mathrm{AlEt}_{2} \mathrm{Cl}\right]=3.5 \mathrm{mmoll}^{-1}$.

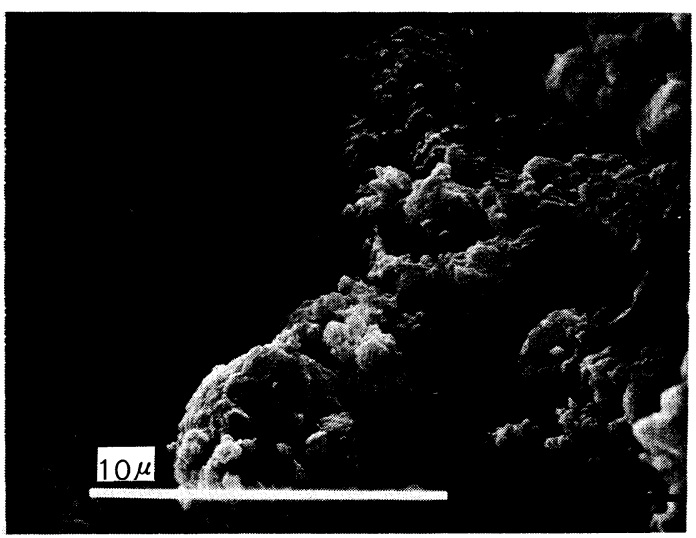

Figure 2. SEM photograph of $\mathrm{TiCl}_{4} / \mathrm{MgCl}_{2} / \mathrm{SiO}_{2}$ catalyst taken at innert atmosphere.

\section{Polymer Texture}

It has been known that the morphology of polyethylene depends on such parameters as the structure of the catalyst, the kinetics of polymerization, the polymerization temperature at the catalyst surface and the mode of crystallization of the polymer chain. ${ }^{1}$ Fibrillar, globular, cobweb, ribbon-like, worm-like, modular, and lamella types of morphology have been observed depending on the catalyst sys-

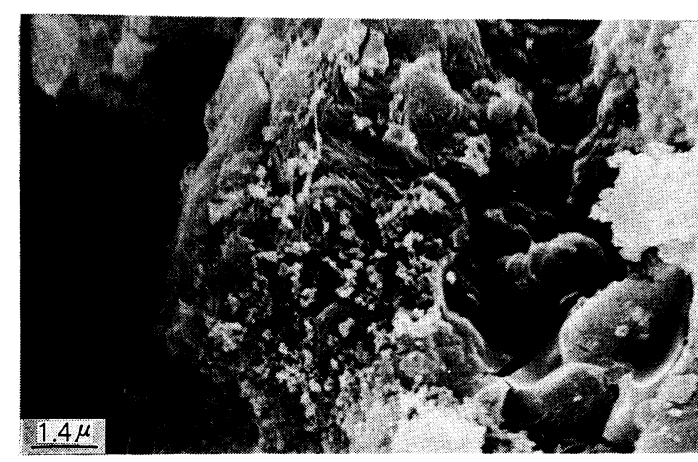

Figure 3. SEM photograph of as-polymerized polyethylene after a $3 \mathrm{~min}$ polymerization time. Polymerization conditions are the same as those in Figure 1.

tems and polymerization conditions. In the case of two polymer samples prepared with the same catalyst but at a different catalyst efficiencies different textures were observed. The exterior surface of the polymer sample obtained at a lower catalyst efficiency was covered by globules, while the polymer samples obtained at higher catalyst efficiency had a worm-like texture. ${ }^{6 c, 13}$

The $\mathrm{TiCl}_{4} / \mathrm{MgCl}_{2} / \mathrm{SiO}_{2}$ catalyst is brittle and porous as shown in Figure 2, so that it can 
undergo encapsulation, followed by fracture. At the reaction condition corresponding to a high catalyst efficiency, polymerization occurs most rapidly on the outside of the particle at the early stage so that each catalyst particles is completely encapsulated by polyethylene. As shown in Figure 3, since the nascent polyethylene is considered to be molten or partially molten resulting from the heat of polymerization, the appropriate heat removal causes the polyethylene to begin to crystallize from the periphery far from the hot catalyst center. When the catalyst is completely encapsulated, a number of adjacent polymer particles expand in diameter, and at the same

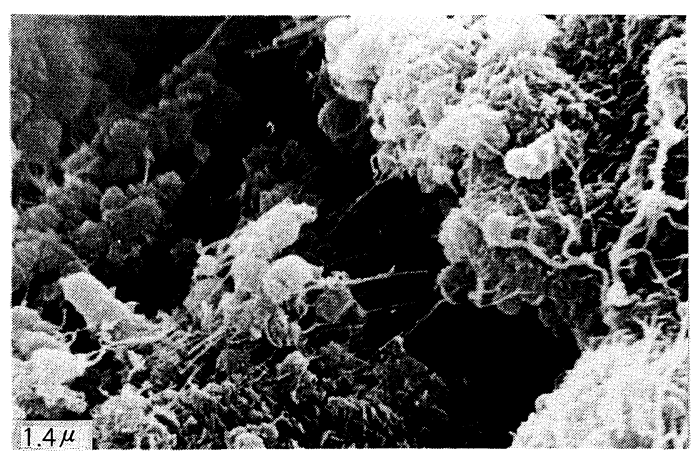

Figure 4. SEM photograph of as polymerized polyethylene after a $5 \mathrm{~min}$ polymerization time. Polymerization conditions are the same as those in Figure 1.

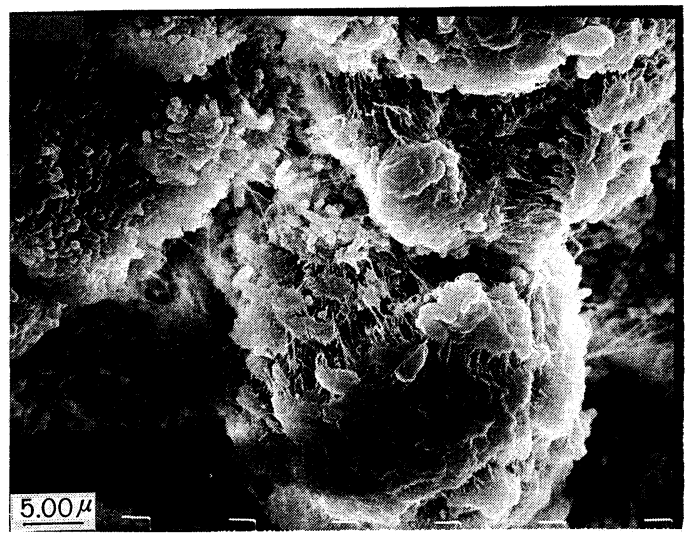

Figure 5. SEM photograph of as polymerized polyethylene after a $10 \mathrm{~min}$ polymerization time. Polymerization conditions are the same as those in Figure 1.

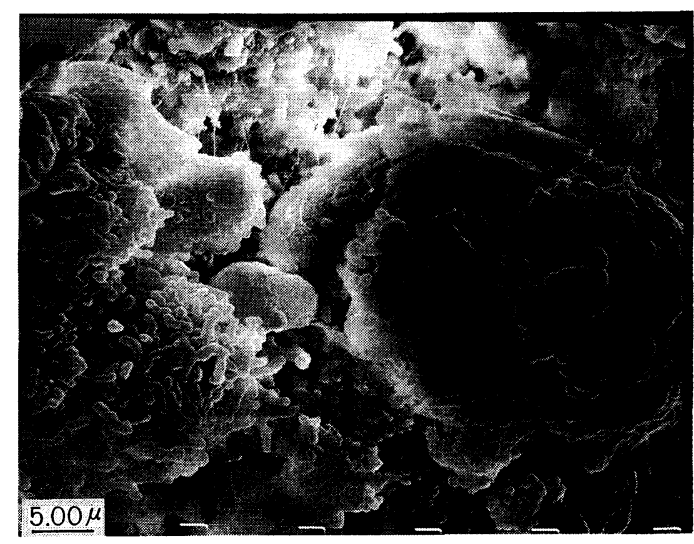

Figure 6. SEM photograph of as-polymerized polyethylene after a $20 \mathrm{~min}$ polymerization time. Polymerization conditions are the same as those in Figure 1.

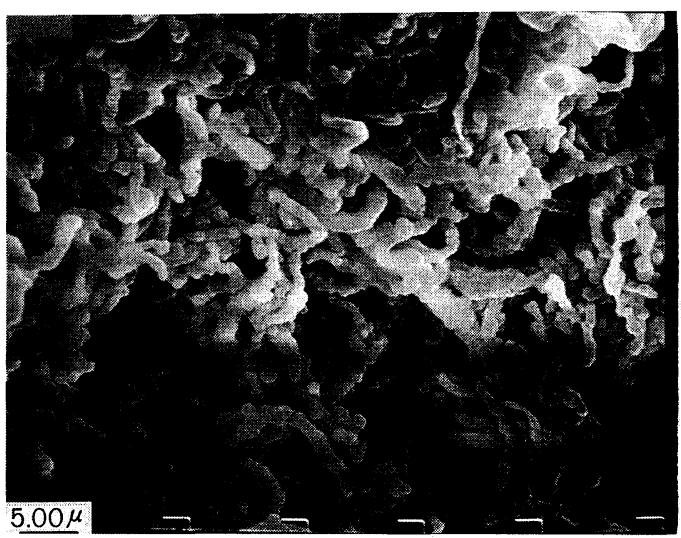

Figure 7. SEM photograph of as-polymerized polyethylene after a $3 \mathrm{~h}$ polymerization time. Polymerization conditions are the same as those in Figure 1.

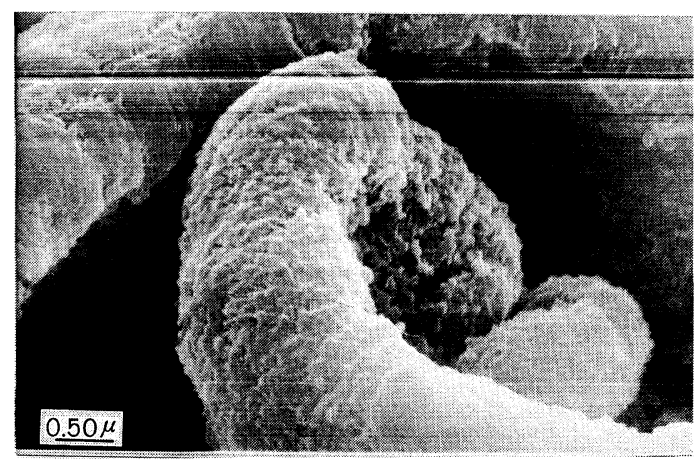

Figure 8. SEM photograph of worm-like polyethylene texture in higher magnification. 
time further polymerization causes fissuring and rupture of the outer layers, allowing easier access for the monomer (Figure 4). As lateral expansion is no longer possible due to increase in the diameter of adjacent polymer particles, continued growth leads to elongation perpendicular to the exterior surface of polymer particles. Figure 5 shows this stage, where polyethylene particles begin to crystallize in the form of a worm, and each expanded particle is inter-connected by very thin fibrils.

After 20 min of polymerization, the portion of worm-like structure increases and the hollow portion of the inner layer decreases as shown in Figure 6. The diameter and length of

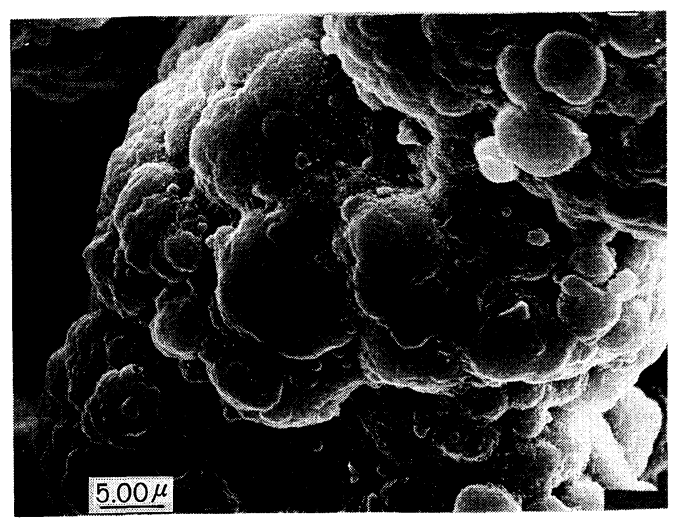

(a)

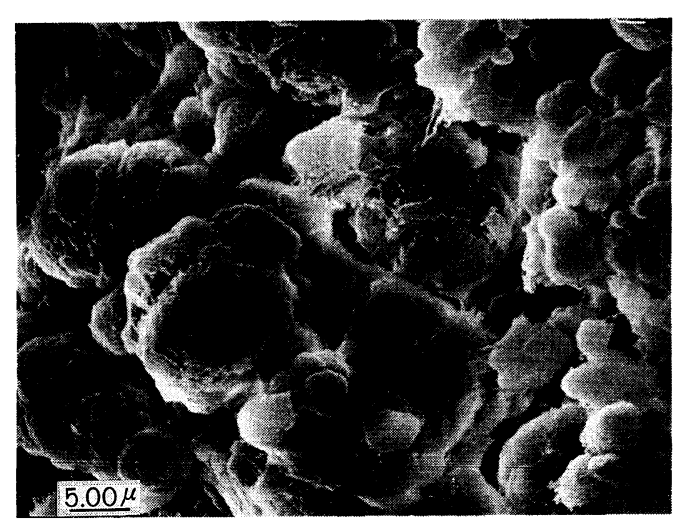

(b)

Figure 9. SEM photographs of as-polymerized polyethylene after a $3 \mathrm{~h}$ polymerization time: (a) prepared at $40^{\circ} \mathrm{C}$; (b) prepared at a limited concentration of $\mathrm{AlEt}_{3}$ $(\mathrm{Al} / \mathrm{Ti}=12)$. the worms increase. From this stage, growth perpendicular to the surface is accelerated and as a result, worms which protrude from the surface constitute a grass texture after $3 \mathrm{~h}$ polymerization as shown in Figure 7 . These explanations agree with the proposal by Chanzy and Munoz-Escalona, that continued growth of globullar polymer particles onto the catalyst surface lead to the formation of worms which protrude from the surface to constitute a grassy texture. ${ }^{6 c, 13}$ The wormlike entities, all having about the same diameter, are several microns long and $1.3 \mu \mathrm{m}$ in diameter, which is relatively thicker than those of polyethylene synthesized with the Stauffer catalyst, $0.5 \mu \mathrm{m} .{ }^{13}$ The worm-like morphology shown in Figure 8 at a higher

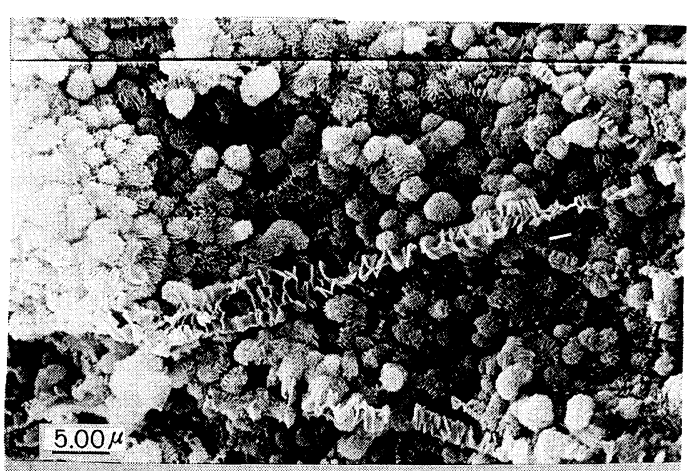

a

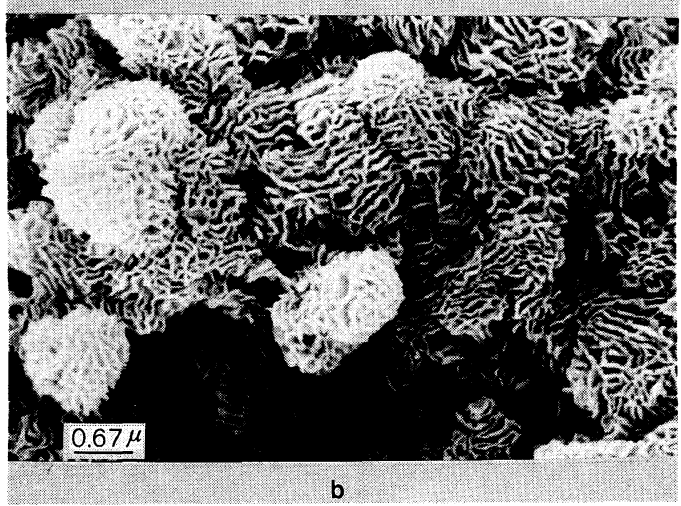

Figure 10. SEM photographs of as-polymerized polyethylene after $1 \mathrm{~h}$ polymerization time. Polymerization conditions are the same as those in Figure 1, but no hydrogen is added. 
magnification is built up by a complicated aggregation of helicoidal ribbon-like crystals with a folded chain macroformation as formerly suggested by several investigators., ${ }^{4,6}$

The surface structure of nascent polyethylene prepared at low catalyst efficiency has a globular morphology, as shown in Figure 9. Figures 9(a) and (b) are polyethylene textures prepared at low temperature $\left(40^{\circ} \mathrm{C}\right)$ and at a limited amount of $\mathrm{Al}\left(\mathrm{C}_{2} \mathrm{H}_{5}\right)_{3}(\mathrm{Al} / \mathrm{Ti}=$ 12). An interesting polyethylene morphology was found when polymerization was carried out at very high catalyst efficiency without hydrogen addition. As shown in Figure 10, folded lamella globules of about $2 \mu \mathrm{m}$ in diameter are formed. The nascent polyethylene has a well defined lamella-globule structure in which the polymer chains are folded and the crystallinity is very high. This type of morphology may be formed by very highly active centers on the surface of the catalyst particles. Because chain transfer is retarded without the addition of hydrogen in comparison with the propagation step, ultra-high molecular weight polyethylene which has high load melt index of $0(\mathrm{~g} / 10 \mathrm{~min})$ and very high density $(0.985$ $\left.\mathrm{g} \mathrm{cm}^{-3}\right)$ is prepared. Those properties are related to the highly crystalline polyethylene texture as shown in Figure 10.

When $\mathrm{AlEt}_{2} \mathrm{Cl}$ is used as the cocatalyst for $\mathrm{TiCl}_{4} / \mathrm{MgCl}_{2} / \mathrm{SiO}_{2}$ catalyst, the polymerization rate is significantly lowered and the acceleration-type rate profile is obtained as shown in Figure 1. The structure of nascent polyethylene texture prepared with the catalyst system is experted to be different from that prepared with the same catalyst combined with $\mathrm{AlEt}_{3}$. As shown in Figure 11, a cobweb structure is obtained. This structure was observed first by Graff et al. for polyethylene prepared with $\mathrm{TiCl}_{4}$ combined with $\mathrm{AlEt}_{2} \cdot{ }^{12}$ In the case of using $\mathrm{Al}$ (iso- $\mathrm{Bu})_{3}$ as the cocatalyst with $\mathrm{TiCl}_{4} / \mathrm{MgCl}_{2} / \mathrm{SiO}_{2}$ catalyst, the rate profile similar to the case of using $\mathrm{AlEt}_{3}$ as a cocatalyst is obtained, even if the overall rate relatively decrease (Figure 1). Accordingly, the

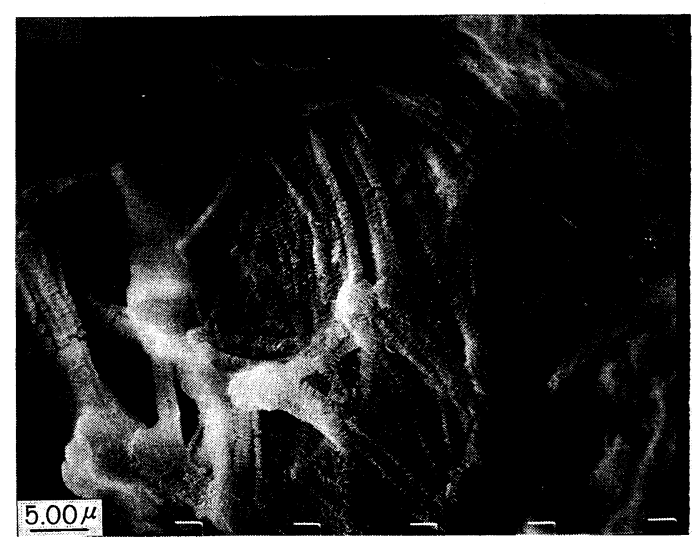

Figure 11. SEM photograph of as-polymerized polyethylene after $3 \mathrm{~h}$ polymerization time. Polymerization conditions are the same as those in Figure 1 in case of using $\mathrm{AlEt}_{2} \mathrm{Cl}$ as the cocatalyst.

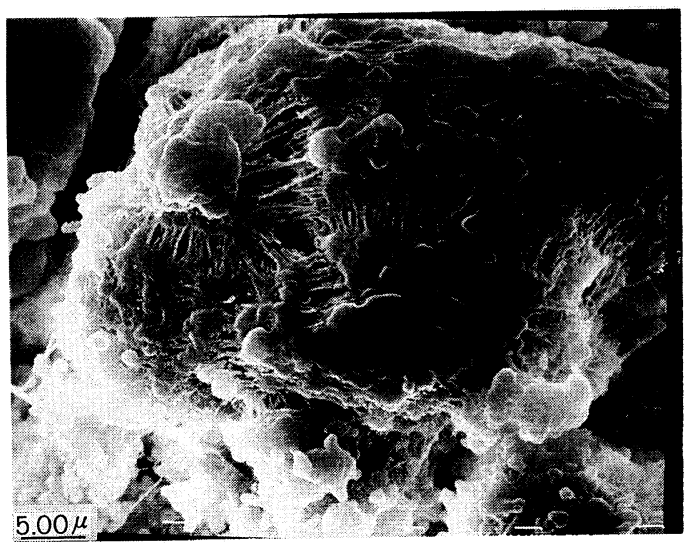

Figure 12. SEM photograph as-polymerized polyethylene after a $3 \mathrm{~h}$ polymerization time. Polymerization conditions are the same as those in Figure 1 in case of using $\mathrm{Al}(\text { iso- } \mathrm{Bu})_{3}$ as a cocatalyst.

polyethylene texture prepared using $\mathrm{Al}$ (iso$\mathrm{Bu})_{3}$ shows a globular texture similar to that prepared using $\mathrm{AlEt}_{3}$ at a low catalyst efficiency as shown in Figure 12.

\section{Polymer Particle Morphology}

The silica gel used as a support was obtained from Strem Chem. (\# 14-7420), predried at $500^{\circ} \mathrm{C}$ in vacuo. The surface area of the silica gel was $350 \mathrm{~m}^{2} \mathrm{~g}^{-1}$ from BET measurement and the average particle size was $35 \mu \mathrm{m}$. Figure 


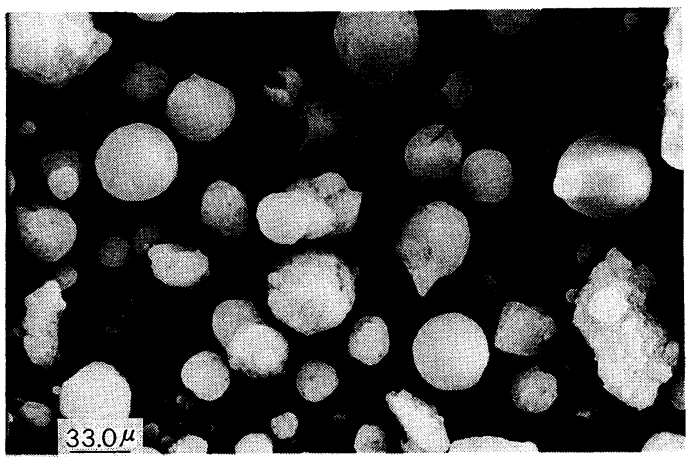

(a)

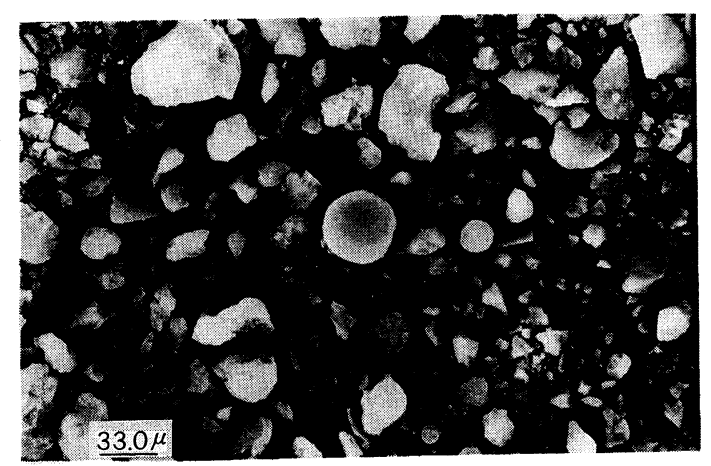

(b)

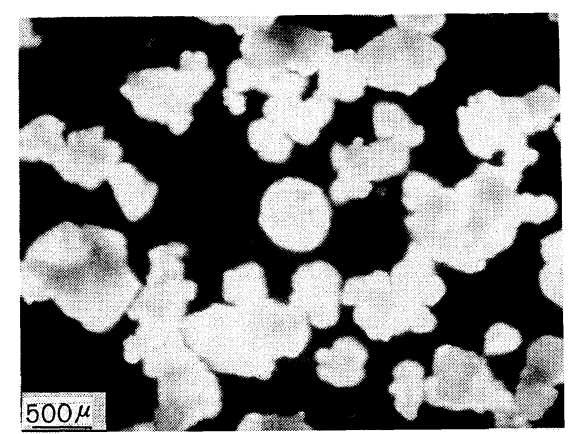

(c)

Figure 13. SEM photographs of (a) silica gel, (b) catalyst particle, and (c) optical microscope photograph of polymer particle.

13(a) shows the particles of silica gel used as a support in the present study. They are spherical and consist of porous aggregates of subparticles. Due to the inherent fragility of the silica gel, the spherical particles are fragmented to irregular particles, and the average particle size decreases to $22 \mu \mathrm{m}$ during preparation of the catalyst as shown in Figure 13(b). By impregnating the catalyst precursor composition, the surface area of silica also decreased considerably, i.e., $350 \mathrm{~m}^{2} \mathrm{~g}^{-1}$ to $180 \mathrm{~m}^{2} \mathrm{~g}^{-1}$.

It has been known that the size, shape, and porosity of the catalyst particle play important roles in regulating the morphology of the progeny polymer. ${ }^{7,8,11} \mathrm{~A}$ number of workers showed that heterogeneous Ziegler-Natta catalysts are capable of replicating their morphology into that of the progeny polymer particles. ${ }^{7,8,11}$ As shown in Figure 13(c), the shape of the progeny polymer particles is rough and irregular, a good replicate of the irregular catalyst particles. Therefore, it is very important to choose an appropriate support and catalyst preparation method in order to control the size and shape of polymer particles.

The overall morphology of polymer particles including average diameter, size distribution, fines content, shape, bulk density, surface roughness, and porosity is affected by the polymerization rate and rate profile. The nature of the support matrix, the nascent polymer viscosity, and the kinetic profile of the polymerization influence the polymer particle growth. The size of catalyst particles prepared by impregnating a catalyst precursor solution to silica gel is less than that of silica gel. The shape of polymer particles is no longer spherical as discussed before. During the early stage of polymerization, the supported catalyst grains are broken into subparticles, followed by gradual buildup of the polymer around the catalyst subparticles. Accordingly the particle size distribution of polymer becomes broader than that of catalyst particles after $1 \mathrm{~h}$ polymerization as shown in Figure 14. The extent of broadening depends to a great extent upon the uniformity of the size and the mechanical strength of silica granules, as a result those of catalyst prepared by the silica gel. The size of polymer particles is determined by the catalyt activity as shown in Figure 14 in which average particle size is smallest when $\mathrm{AlEt}_{2} \mathrm{Cl}$ is used as the cocatalyst. 


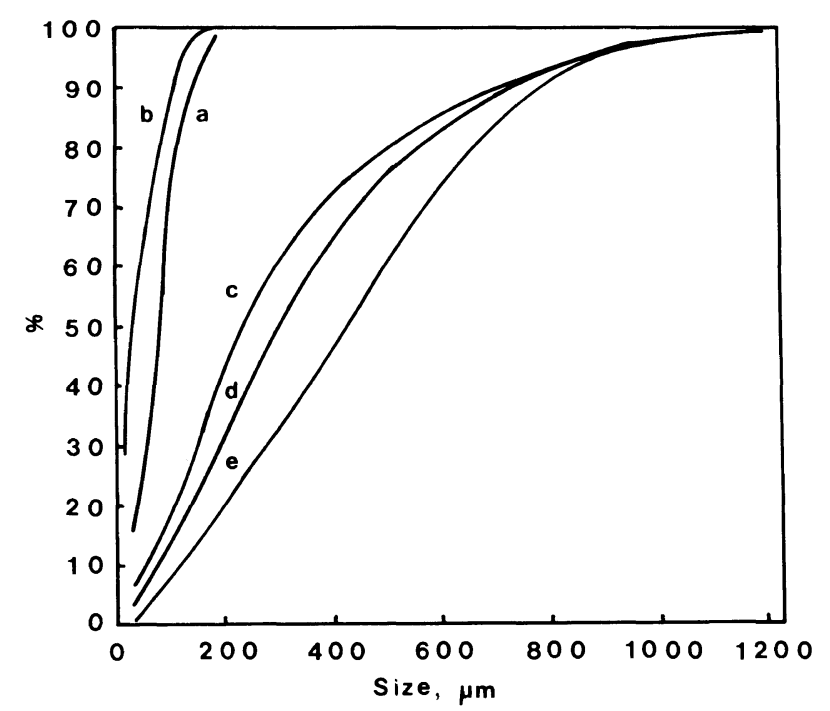

Figure 14. Particle size distribution of (a) silica gel, (b) catalyst, and polyethylene synthesized with a different cocatalyst: (c) $\mathrm{AlEt}_{2} \mathrm{Cl}$, (d) $\mathrm{Al}(\text { iso-Bu })_{3}$, and (e) $\mathrm{AlEt}_{3}$.

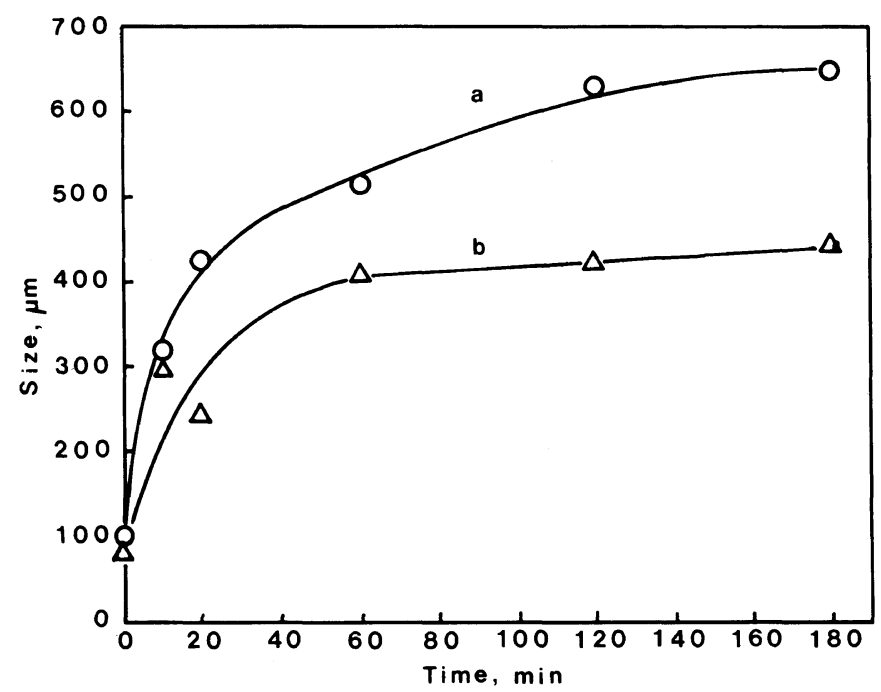

Figure 15. Variation of (a) median and (b) dispersion of polyethylene particles as a function of polymerization time.

The median $\left(\mathrm{P}_{50}: 50\right.$ th percentile $)$ and the dispersion $\left(\left(\mathrm{P}_{84}-\mathrm{P}_{16}\right) / 2, \mathrm{P}_{84} ; 84\right.$ th percentile, $\mathrm{P}_{16}$; 16th percentile) of polyethylene particles as a function of polymerization time are shown in Figure 15. Particles grow rapidly at the early stage of polymerization (within 20 minutes). Two hours following polymerization, the me- dian and the dispersion of polyethylene particles increase slightly, and fineness (no greater than $125 \mu \mathrm{m}$ in diameter) becomes negligible after a polymerization time of $2 \mathrm{~h}$. Rapid growth of polyethylene particles is related to the polymerization rate which reaches a maximum within 20 minutes as shown in Figure 1. 
The effect of polymerization temperature on the particle of polyethylene particles is shown in Figure 16. Lower polymerization temperature increases monomer concentration in the solvent ( $n$-hexane) and lowers the polymerization rate. Accordingly, the median of polyethylene particles becomes large as the polym- erization temperature increases. According to the previous kinetic study, ${ }^{10}$ the rate of ethylene polymerization with the $\mathrm{TiCl}_{4} /$ $\mathrm{MgCl}_{2} / \mathrm{SiO}_{2}$ catalyst combined with $\mathrm{Al}\left(\mathrm{C}_{2} \mathrm{H}_{5}\right)_{3}$ showed a maximum around a polymerization temperature of $80^{\circ} \mathrm{C}$. The rate of polymerization decreased sharply at $90^{\circ} \mathrm{C}$, while the

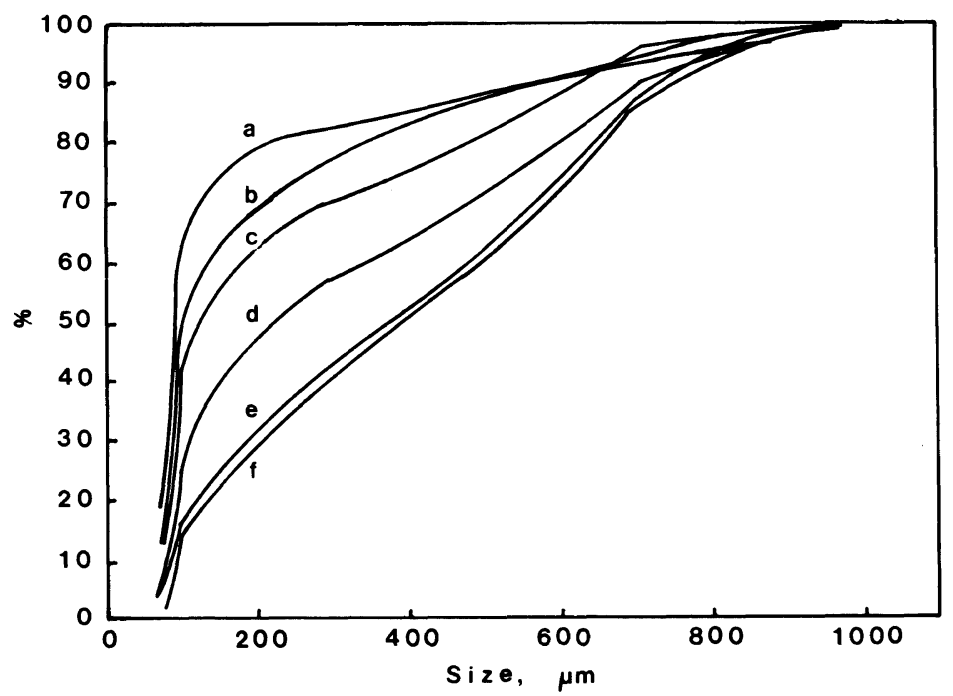

Figure 16. Effect of polymerization temperature on particle size distribution of nascent polyethylene after a $1 \mathrm{~h}$ polymerization time. Polymerization conditions: $P=12.4 \mathrm{~kg} \mathrm{~cm}^{-2} ; P_{\mathrm{H} 2}=1.4 \mathrm{~kg} \mathrm{~cm}^{-2} ;[\mathrm{Ti}]=$ $1.785 \times 10^{-5} \mathrm{~mol} ;\left[\mathrm{AlEt}_{3}\right]=4.35 \mathrm{mmoll}^{-1}$; (a) $T=40^{\circ} \mathrm{C}$, (b) 50 , (c) 60 , (d) 70, (e) 80 , and (f) 90 .

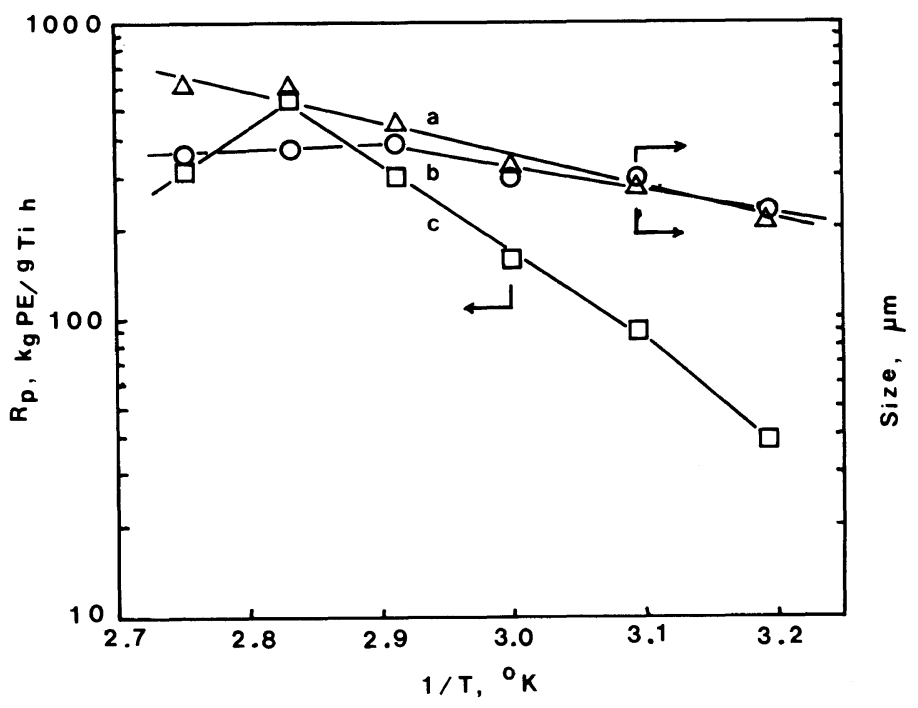

Figure 17. Arrhenius plot of polymerization temperature vs. (a) median, (b) dispersion, and (c) polymerization rate. 
time to reach the maximum rate decreased. The average particle size of polyethylene particles at $90^{\circ} \mathrm{C}$ is not less than that of polyethylene particles polymerized at $80^{\circ} \mathrm{C}$. It increases slightly at $90^{\circ} \mathrm{C}$ in spite of the considerable decrease in the average polymerization rate as shown in Figure 17. The increase of polymer particles prepared at $90^{\circ} \mathrm{C}$ is due to the acceleration of the formation of large particles owing to the rapid activation of the polymerization rate. However, the rate of polymerization drops rapidly due to the unstability of active sites, resulting in a smaller number of active sites onto the subparticles. Accordingly the amount of polymer produced per catalytically active site does not decrease. The dispersion of polymer particles, which indicates particle size distribution, does not change much above $70^{\circ} \mathrm{C}$.

Bulk density decreases as the polymerization temperature increases as shown in Figure 18. The polyethylene particles prepared at high catalyst efficiency are porous due to the action of porous worm-like texture and incomplete crystallization as already explained in the previous section. According to previous kinetic results, ${ }^{10}$ the initial polymerization rate of ethylene increased as the polymerization temperature increased for the $\mathrm{TiCl}_{4} / \mathrm{MgCl}_{2} / \mathrm{SiO}_{2}$ catalyst combined with $\mathrm{AlEt}_{3}$. The rapid initial polymerization rate and low concentration of ethylene in $n$-hexane at high polymerization temperatures lead to the speculation that there may be monomer diffusion and external mass transfer limitations in the polymerization centers, resulting in more void volume inside polymer particles. Polymerization at lower temperatures allows ethylene to fill up the inside cavity of the catalyst to form a compact polymer [Figure 9(a)] due to the slow initial polymerization rate, resulting less void volume inside polymer particles and more time to be crystallized.

The effect of the concentration of $\mathrm{Al}\left(\mathrm{C}_{2} \mathrm{H}_{5}\right)_{3}$ on the particle size distribution is illutrated in Figure 19. The polymerization rate was maximum around a $\mathrm{Al} / \mathrm{Ti}$ ratio of 60 , followed by slight decrease, and a considerable amount of aluminium alkyl did not participate in the formation of active sites but become adsorbed on the surface of silica in a manner ineffective for polymerization. ${ }^{10}$ The time to reach the maximum rate became shorter as the $\mathrm{Al} / \mathrm{Ti}$ ratio increased due to the rapid activation of the active sites. Accordingly, the high ratio of $\mathrm{Al} / \mathrm{Ti}$ exerts a good influence on the formation of large particles regardless of the decrease in average polymerization rate. This can be ex-

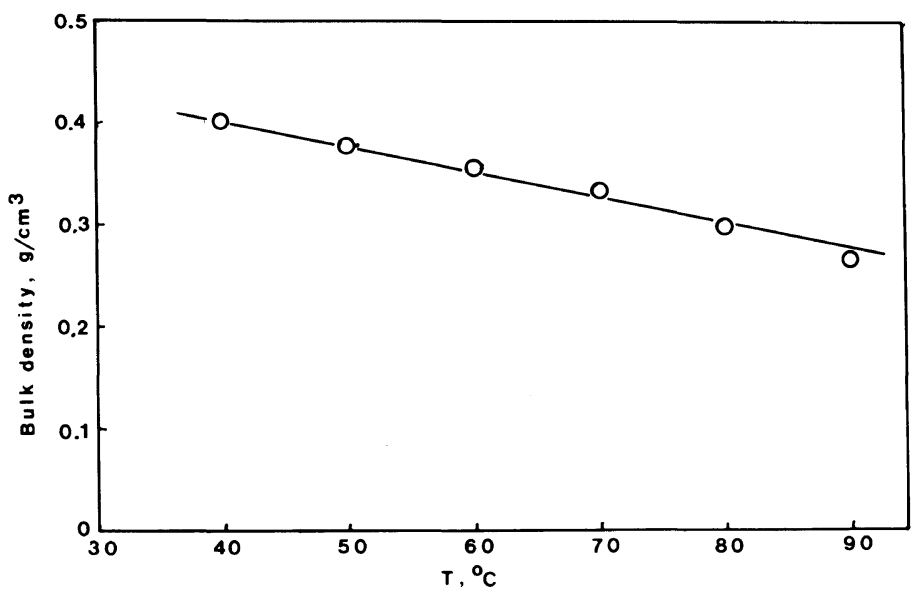

Figure 18. Dependence of bulk density of polyethylene on polymerization temperature. Polymerization conditions are the same as those in Figure 16. 


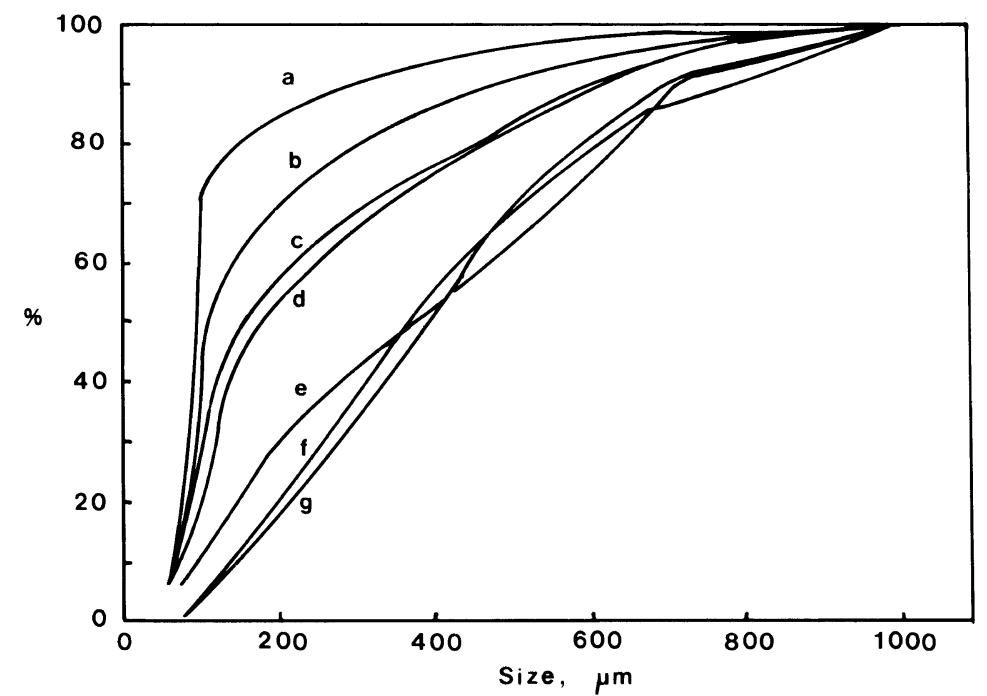

Figure 19. Effect of $\mathrm{Al}\left(\mathrm{C}_{2} \mathrm{H}_{5}\right)_{3}$ concentration on particle size distribution of nascent polyethylene after $1 \mathrm{~h}$ polymerization time. Polymerization conditions: $P=12.4 \mathrm{~kg} \mathrm{~cm}^{-2} ; P_{\mathrm{H} 2}=1.4 \mathrm{~kg} \mathrm{~cm}^{-2} ; T=80^{\circ} \mathrm{C} ;[\mathrm{Ti}]=$ $1.785 \times 10^{-5}$; (a) $\left[\mathrm{AlEt}_{3}\right]=0.12 \mathrm{mmoll}^{-1}$, (b) 0.48 , (c) 0.97 , (d) 1.21 , (e) 1.93 , (f) 4.35 , and (g) 10.38 .

plained by the fact that a polyethylene particles prepared at high $\mathrm{Al} / \mathrm{Ti}$ ratio are very porous, because the formation of a highly porous worm-like texture is favored. On the other hand, a relatively dense globular texture is obtained at low $\mathrm{Al} / \mathrm{Ti}$ ratio as shown in Fig. 9(b), resulting in smaller average particle size and a narrow particle size distribution.

Acknowledgements. The authors thank the Ministry of Science and Technology in Korea for granting the research fund (No. 2710, No. 3710, and No. 4900). The donation of ethylene and chemicals from Yukong Ltd. and Korea Petrochemical Co. is also greatly appreciated.

\section{REFERENCES}

1. J. Boor, Jr., "Ziegler-Natta Catalyst and Polymerization," Acadmic Press, New York, N. Y., 1979.

2. B. Wunderlich, Adv. Polym. Sci., 5, 568 (1968).

3. P. Ingram and A. Schindler, Makromol. Chem., 111,
267 (1968).

4. P. Blais and R. St. J. Manley, J. Polym. Sci., A-1, 6, 291 (1968).

5. H. D. Chanzy, J. F. Revol, R. H. Marchessault, and A. Lamanda, Kolloid-Z. Z. Polym., 251, 563 (1973); b) H. D. Chanzy, E. Bonjour, and R. H. Marchessault, Kolloid-Z. Z. Polym., 252, 8 (1974).

6. a) A. Munoz-Escalona and A. Parada, Polymer, 20, 474 (1979); b) ibid., 20, 859 (1979); c) J. Cryst. Growth, 48, 250 (1980).

7. P. Mackie, M. N. Berger, B. M. Grieveson, and D. Lawson, J. Polym. Sci., B, 5, 493 (1967).

8. A. Munoz-Escalona, J. G. Hernadez, and J. A. Gallardo, J. Appl. Polym. Sci., 29, 1187 (1984).

9. B. E. Wagner, G. L. Goeke, and F. J. Karol, Eur. Patent Appl. 55605 (1981).

10. I. Kim, J. H. Kim, and S. I. Woo, J. Appl. Polym. Sci. (1989), in press.

11. C. W. Hock, J. Poly. Sci., A-1, 4, 3055 (1966).

12. R. J. L. Graff, G. Kortleve, and C. G. Vonk, J. Polym. Sci., B, 8, 735 (1970).

13. J. Wristers, J. Polym. Sci., Polym. Phys. Ed., 11, 1601 (1973).

14. A. Munoz-Escalona, in "Transition Metal Catalyzed Polymerization,” R. P. Quirk, Ed., MMI Press, New York, N. Y., 1983. 